\section{Spontaneous Pneumothorax}

This is included as it accounted for five cases. It had a sudden onset with pain and a variable degree of dyspnoea. In four there was no previous or subsequent chest trouble. The fifth patient, an elderly lady of 68 , had a history of recurring coughs and developed a valvular pneumothorax. She died in hospital.

\section{Conclusion}

It will be seen that these numerous cases from a single general practice present a different picture from those seen in hospital work. This is, of course, due to the fact that only the cases which cannot be managed at home are sent into the hospital wards. This series was relatively benignthus only two patients died in this group and nine required admission to hospital. This type of case has received almost no attention in the past, and it is felt that there is a need for further study of this group. A simpler and more precise method of classifying acute chest diseases, which should be based on aetiological grounds, is also necessary.

\section{Summary}

A clinical report is presented on 164 cases of acute chest disease as seen in a general practice over a period of two years.

Acute bronchitis accounted for 66 cases. Subdivision into primary and secondary groups is made.

Seventy-seven cases of pneumonia were seen. Only three of these were the primary " classical "pneumonias. The common type was a localized area of inflammation with no clinical evidence of consolidation. On the aetiology of this subgroup it is difficult to dogmatize, but three possibilities are put forward: (1) infection due to an identifiable virus ; (2) an infection due to a specific unidentifiable agent ; or (3) the condition might in fact be an aspiration pneumonia.

The other conditions which produced the acute chest were pleurisy, severe asthma, and spontaneous pneumothorax.

A plea is made for a simpler and more logical classification of acute chest diseases, and the need for further research on these conditions is stressed.

I wish to express my gratitude to the pathological and radiological departments of the local hospital for their assistance, especially Dr. A. C. Glendinning and Dr. John Keall, and also to the Virus Reference Laboratory, Colindale.

\section{REFERENCES}

Brock, R. C. (1946). Anatomy of the Bronchial Tree. Oxford Univ. Press, London.

Fry, J. (1951). Brittsh Medical Journal, 2, 1374

- (1952). Ibld., 2, 249.

Lees, A. W. (1950). Ibid., 2, 1138 .

Nicholson, H. (1950). Lancet, 2, 549, 605.

Quinn, L. H., and Meyer, O. O. (1929). A rch. Otolaryng., Chicago, 10, 152

Ramsay, H., and Scadding, J. G. (1939). Quart. J. Med., 8, 79.

Reimann, H. A. (1943). Bull. N..Y. Acad. Med., 19, 177

Robertson, P. W., and Morle, K. D. F. (1951). British Medical Journal, 2 994.

Scadding, J. G. (1948). Lancet, 1, 89

(1951). Proc. roy. Soc. Med., 44, 511

A radical change in the footwear of this year's British Everest expedition is announced. Instead of the familiar heavily nailed leather climbing-boots, the assault parties will wear a much lighter boot with soles of artificial rubber and glacé kid uppers. The boots are insulated inside with a layer of kapok nearly an inch thick. It is pointed out that lightness and warmth are far more important qualities than durability and water-resistance for the Everest assault. The boots, which have already been tried in the Alps, will be required only for a few days' use, and at the temperatures high on Everest water is unlikely to be encountered (The Times, January 6).

\section{DISSECTING AORTIC ANEURYSM : A VARIED CLINICAL PICTURE}

\author{
BY
}

\author{
R. K. MacCUISH, M.B., M.R.C.P. \\ Senior Medical Registrar, Thoracic Surgical Centre, \\ Shotley Bridge Hospital, Co. Durham
}

Dissecting aneurysm was first described by Morgagni in 1761. In 1934 Shennan published his exhaustive monograph on the subject, having been able to collect over 300 cases from the literature. A significant point arising from this report was that only six cases were diagnosed before death.

The correct ante-mortem diagnosis may present much difficulty for two reasons. (1) Bizarre symptoms and signs may occur, and disease of other systems may be simulated. (2) It is a somewhat uncommon condition in hospital practice. Many cases die suddenly and therefore fall into the hands of the coroner. In San Francisco, Mote and Carr (1942) compared the incidence at coroners' post-mortem examinations with that at hospital post-mortem examinations. They found three times as many in the former as in the latter, and a similar state of affairs may well hold in this country.

The clinical picture which has come to be recognized as typical of aortic dissection is that of the sudden onset of severe tearing thoracic pain accompanied by shock and radiating down both legs. This view of dissecting aortic aneurysm may have obscured the correct diagnosis in many instances in the past, and patients may have been subjected to operative intervention when this condition was not borne in mind. It is the purpose of this note to suggest that aortic dissection may often be a silent process and may progress with only minor symptoms for months or years.

Five cases are described, illustrating the paucity of symptoms and the tendency to simulate other diseases.

\section{Case 1}

A 53-year-old woman was admitted to hospital with 30 years' history of epigastric pain relieved by food and alkaline powders. For two to three years previously the pain had radiated through to the back. Two weeks before admission she developed a sudden weakness in the left arm and left leg. Twelve hours before admission she had a severe attack of epigastric pain radiating through to the back. She persisted that the sudden pain which occurred before admission was of the same nature as that which she attributed to her dyspepsia.

On examination her general condition was reasonably good. The pulse was regular and the blood pressure 230/ 130. The apex beat was not displaced. A systolic murmur was present over the praecordium. There was definite muscular weakness of the left arm and leg, with exaggerated reflexes and a doubtful plantar response. There was no abnormal finding in any other system.

Investigation.-Haemoglobin, $56 \%$; white cells, 15,000 (polymorph leucocytosis). Urine: albumin + , granular and hyaline casts, red blood cells present. The blood urea was $70 \mathrm{mg}$. per $100 \mathrm{ml}$. The Wassermann reaction was negative. An electrocardiogram showed inversion of $T_{1}, T_{2}$, and T ER 4.

The epigastric pain persisted, resisting all the usual methods of treatment. Strong sedation had to be employed. Five days after admission a small effusion was detected clinically at the left lung base, and this extended up to the spine of the scapula during the next 48 hours. $X$-ray examination of the chest revealed almost complete opacity of the left hemithorax. Repeated attempts 
at aspiration gave only a few drops of blood-stained fluid. The patient went slowly downhill and died 17 days after admission.

Necropsy.-Hypertrophy of the left ventricle and a marked atheroma of the aorta were found. There was a massive effusion of clotted blood in the left hemithorax. A dissecting aneurysm began in the ascending arch of the aorta and extended down to the renal arteries. In the thorax the aneurysm had developed a secondary fusiform swelling, the wall of which was composed of old laminated film clot. This had ruptured, to give rise to the haemothorax. There was no evidence of peptic ulcer.

\section{Case 2}

A 71-year-old night watchman was admitted with two years' history of intermittent attacks of left-sided abdominal pain. It sometimes radiated round to the lumbar region and to his back, but was never severe enough to make him stay away from his work. On the day of admission the pain was so severe that he collapsed and was brought to hospital.

On examination his general condition was reasonably good; blood pressure, 200/120. There were no abnormal physical signs. The urine showed: albumin ++ , many red blood cells, no casts. The blood urea was $180 \mathrm{mg}$. per $100 \mathrm{ml}$. A radiograph of the chest showed dilatation of the aortic knob, suggesting an aneurysm. $X$-ray examination of the abdomen and spine showed nothing abnormal.

The pain persisted and at times was severe enough to necessitate strong sedation. The day after admission he passed only $6 \mathrm{oz}$. $(170 \mathrm{ml}$.) of urine, and on the second day he became anuric. Cystoscopy was performed. The bladder and both ureteric orifices were normal. Ureteric catheters could not be passed. The left kidney was therefore explored. It was found to be swollen and pale, and the surface was stippled with multiple infarcts. No urine was present in the renal pelvis. The patient died without recovering consciousness.

Necropsy.-The aorta was grossly atheromatous. A dissecting aneurysm was present, beginning below the renal arteries and extending up to the aortic arch, where it stopped short. This occluded the renal arteries. Both kidneys were completely infarcted. There was pronounced hypertrophy of the left ventricle.

\section{Case 3}

A 60-year-old woman was admitted with a history of progressive dyspnoea on exertion for nine years and swelling of her feet for two years. For four months she had experienced a heavy substernal pain, not particularly related to exertion or to food. It sometimes lasted up to 30 minutes, but was never unduly severe.

Examination showed the patient to be very obese and obviously myxoedematous. She was dyspnoeic and cyanosed at rest. Her blood pressure was $190 / 110$; pulse regular ; apex beat displaced to the left. The heart sounds were normal. Oedema of feet was present and there were rales at both lung bases. The urine showed: albumin ++ , many hyaline casts, no red blood cells. The blood urea was $58 \mathrm{mg}$. per $100 \mathrm{ml}$. An electrocardiogram showed RS-T depression in Leads I, II, and III, and T inversion in CR 4 and CR 7.

On the day after admission she suddenly collapsed and became deeply cyanosed, with gasping respirations, sweating, and bounding pulse. She slowly recovered consciousness, and during the following week became less dyspnoeic and cyanosed. At the end of the first week she had another attack similar to that described above, and died soon afterwards.

Necropsy.-The aorta was grossly atheromatous. A dissecting aneurysm was found, beginning in the aortic arch and extending to just above the origin of the renal arteries. The left ventricle was hypertrophied. The thyroid was small and atrophic. There were no other gross pathological findings.

\section{Case 4}

A 48-year-old police officer suddenly lost consciousness while waiting in a dentist's surgery. He was taken to hospital, and on admission was violent and uncontrollable, and threw himself around on the receiving-room floor. After three hours he recovered consciousness fully. His blood pressure was $90 / 60$. The lips were very cyanosed. There was obvious weakness of the left arm and leg. The left arm was cold and discoloured and no arterial pulsation could be felt. The heart was fibrillating. The reflexes were somewhat increased in the left arm and leg, and the left plantar response was extensor. The patient died suddenly the next day.

Necropsy.-There was a large dissecting aneurysm, beginning $\frac{1}{2}$ in. $(1.3 \mathrm{~cm}$.) above the aortic valve and extending as far as the coeliac axis, surrounding the innominate and left common carotid vessels, and effusing extensively along the left subclavian artery. It had ruptured into the pericardium and extended around both lung roots. There was considerable hypertrophy of the left ventricle.

\section{Case 5}

A 53-year-old railway signalman was admitted to hospital with a history that four weeks previously, while standing in the street, he had a sudden severe pain in the chest radiating to both groins. This pain passed off in a minute and left his right leg numb and weak. The whole condition passed off in 15 minutes, and nothing like it recurred up to his admission to hospital.

On examination his blood pressure was $260 / 170$. His heart was not clinically enlarged. A soft diastolic murmur was heard at the left sternal border. There were no other abnormal clinical findings. The urine showed: albumin ++ and excess of leucocytes in deposit. The blood urea was $66 \mathrm{mg}$. per $100 \mathrm{ml}$. The Wassermann reaction was negative. A blood count showed: $\mathrm{Hb}, 12.3 \mathrm{~g} . \%$; white cells, 10,500. Cardioscopy revealed slight enlargement of the left ventricle. An electrocardiogram showed left ventricular hypertrophy.

A course of oral hexamethonium bromide was begun 10 days after admission, but 12 days later the patient awoke during the night complaining of upper abdominal pain and collapsed. He was found to be comatose and sweating profusely, and his blood pressure fell to $80 / 60$. Consciousness was recovered fairly quickly, but two similar episodes followed at three-day intervals. After his first attack he had a tender swelling in the right loin which progressively increased in size. The blood urea rose to $480 \mathrm{mg}$. per $100 \mathrm{ml}$. He slowly became comatose, and died one month after admission to hospital.

Necropsy.-A dissecting aortic aneurysm was found, beginning in the arch of the aorta and tracking down the vessel beyond the origin of the renal arteries. There was a large retroperitoneal haemorrhage on the right side, surrounding the right kidney and extending from the lower edge of the right lobe of the liver into the pelvis. Both kidneys showed the changes of pyelonephritis. The heart was generally enlarged, with hypertrophy and dilatation of the left ventricle.

\section{Discussion}

Age and Sex Incidence.-No age group is free from this disease. The fifth and sixth decades claim the largest proportion of subjects, but a not inconsiderable number fall into the earlier periods. One of the youngest patients was a 22-year-old hypertensive male in whom multiple tears were found after death (Flaxman, 1942). Some indication of the incidence in the younger age groups is given by Schnitker and Bayer (1944), who found that $24 \%$ of their series were under 40 . Males are subject to this disease more than females. Baer and Goldburgh (1948) suggest that as many as two-thirds of all cases occur in males.

Pathology.-It was originally believed that atheromatous degeneration was responsible for the initiation of dissection. 
Shennan (1934), however, pointed out that most dissections begin in areas relatively free from atheroma. Atheromatous degeneration is seldom very severe in the first part of the aorta, where dissection most often begins. Cystic degeneration of the media, frequently found in aortic dissection, is now generally accepted as the initial lesion. Some writers have stressed the importance of sudden strain in initiating the tear, but such a history is often absent. In none of the above five cases was sudden strain an important factor.

\section{Clinical Picture}

A wide diversity in the presenting symptoms is manifest in these cases, ranging from complete absence of pain, as in Case 4, to the classical picture of severe chest pain radiating to the groin in Case 5. In the latter, however, the symptoms were of momentary duration only.

Silent dissection may not be so uncommon. Baer and Goldburgh (1948), in reviewing a series of 44 cases, found 24 which gave no history whatever of pain. There does not seem to be any very obvious reason why some cases should be painful. It may be that rapidity of dissection is a related point. In Case 4 , in which there was no history of pain, the post-mortem findings pointed to a recent dissection, and from a clinical aspect dissection had extended from the origin of the left subclavian artery to the coeliac axis in 24 hours - that is, the time between the onset of symptoms and death.

The experience of these cases certainly does not support the view of Paullin and James (1948), who consider that pain may be absent when dissection proceeds slowly. In Cases 1, 2, and 3 pain was a prominent feature in the history, yet the pathological findings pointed to chronic dissection. Cases 1 and 2 are instructive in demonstrating how slight may be the incapacity resulting from chronic dissection. In Case 1 , in view of the absence of peptic ulceration at necropsy, it is most probable that symptoms in the later two to three years of life were due to the aortic disease, yet her disability was never severe enough to warrant hospital admission up to the time of her last illness. Case 2 made light of his two-years history of left-sided abdominal pain, yet there can be no question that his symptoms were due to the dissection of the aorta.

That dissecting aneurysm of the aorta can simulate primary disease in other systems is readily understood on anatomical grounds. Extensive dissection to the carotid vessels may show as cerebral symptoms, to the subclavian arteries as vascular lesions in the arms, to the coeliac axis and renal vessels as abdominal emergencies or renal disease respectively. When, in addition, pain is minimal or absent the clinical diagnosis may become still more obscure. Cases 2 and 5 bear this out.

Renal involvement was the presenting feature in Case 2 and a later manifestation in Case 5. Blain, Glynn, and Hiratzka (1945) have reviewed the literature up to that time bearing on the question of renal involvement in aortic dissection.

From the neurological aspect Weisman and Adams (1944) have commented on the frequency of neurological symptoms in this disease. They mention that $30 \%$ of such cases coming to necropsy at the Boston City Hospital had such symptoms. In addition the combination of neurological and vascular lesions in a limb in any patient should immediately arouse the suspicion of aortic dissection.

Electrocardiographic Findings.-These are not infrequently a further source of confusion in reaching a diagnosis. The coronary blood flow is said to be obstructed by extension of the dissection to the coronary ostia or by compression of the vessels from pericardial haemorrhage, thus giving rise to the electrocardiographic picture of cardiac infarction. Bourne and Mills (1946) have reported two cases in which neither of the above explanations sufficed to explain the electrocardiographic findings. There the serial changes compatible with cardiac infarction were found in life, but at necropsy there was no evidence of cardiac infarc- tion. Oram and Holt (1950) have reviewed the literature on this aspect, and suggested some features which might be helpful in the differential diagnosis.

\section{Summary}

Five cases of dissecting aneurysm of the aorta are described. It is suggested that less importance should be attached to the history of severe thoracic pain than in the past. Aortic dissection may often be a silent process or present with the minimum of symptoms over a prolonged period. The tendency to simulate other diseases is a prominent feature.

I am indebted to Dr. J. K. Rennie, Bradford Royal Infirmary, for permission to publish Cases 1-4, to Dr. W. G. A. Swan, Newcastle General Hospital, for Case 5, to Mr. C. L. O. Macalister for his notes of the cystoscopy and operation on Case 2, and to Drs. R. Turner and B. Smith for access to their necropsy reports.

\section{REFERENCES}

Baer, S., and Goldburgh, H. L. (1948). Amer. Heart J., 35, 198. Blain, A., Glynn, T. P., and Hiratzka, T. (1945). J. Urol., 53, 753 Bourne, G., and Mills, P. J. W. (1946). Brit. Heart J., 8, 181. Flaxman, N. (1942). Amer. Heart J., 24, 654. Morgagni, G. B. (1761). De sedibus et causts morborum, 26, art. 21 Mote, C. D., and Carr, J. L. (1942). Amer. Heart J., 24, 69. Oram, S., and Holt, M. C. (1950). Brit. Heart J., 12, 10. Paullin, J. E., and James, D. F. (1948). Postgrad. Med., 4, 291. Schnitker, M. A. and Bayer, C. A. (1944). Ann. tntern. Med., 20, 486 Shennan, T. (1934). Spec. Rep. Ser. med. Res. Coun., Lond., No. 193 Weisman, A. D., and Adams, R. D. (1944). Brain, 67, 69.

\section{LEAKING ABDOMINAL ANEURYSMS TWO UNUSUAL CASES}

BY

\section{J. WOODROW BETTS, F.R.C.S.}

AND

\section{B. C. ROWLANDS, F.R.C.S.}

Surgical First Assistants, the Royal Infirmary, Sheffield

Aneurysm of the abdominal aorta is an uncommon condition whose mode of presentation is unusually varied. The two cases presented here are recorded for their similar and misleading clinical features. They presented as strangulated inguinal herniae.

The importance of recognizing that aortic aneurysm may present as an acute abdominal emergency lies in the fact that unnecessary operation may thereby be obviated. Both the ruptured and the unruptured aneurysm present these difficulties of diagnosis.

\section{Case 1}

A man aged 69 was admitted as an emergency case on December 2, 1948, with a provisional diagnosis of strangulated right inguinal hernia. When seen after admission he was complaining of severe abdominal pain, which had come on suddenly the previous afternoon. He complained of nausea, and had vomited.

On examination he had a temperature of $100^{\circ} \mathrm{F} .\left(37.8^{\circ} \mathrm{C}\right.$.) and a pulse rate of 100 . Examination of his abdomen revealed a tender irreducible swelling in the right inguinal region. His abdomen presented generalized rigidity, and bowel sounds were absent on auscultation. A provisional diagnosis was made of incarcerated right inguinal hernia, with probably strangulation and peritonitis.

Laparotomy (B. C. R.) revealed diffuse retroperitoneal extravasation of blood involving both the posterior and the anterior abdominal parietes. A large non-pulsatile mass was felt in the position of the abdominal aorta. It was then realized that the case was one of ruptured abdominal aneurysm, the external swelling being due to extravasated blood escaping through the inguinal canal. 